\title{
Prevalence of Urolithiasis by Ultrasonography Among Patients with Gout: A Cross-Sectional Study from the UP-Philippine General Hospital
}

This article was published in the following Dove Press journal: Research and Reports in Urology

\author{
Michael Tee $\mathbb{D}^{1,2}$ \\ Ceferino Lustre II (D) ${ }^{3}$ \\ Aedrian Abrilla $\mathbb{D}^{4}$ \\ Ivy Elline Afos ${ }^{2}$ \\ Johanna Patricia Cañal $\mathbb{D}^{5}$ \\ 'Department of Physiology, College of \\ Medicine, University of the Philippines \\ Manila, Manila, Philippines; ${ }^{2}$ Division of \\ Rheumatology, Department of Medicine, \\ Philippine General Hospital, University of \\ the Philippines Manila, Manila, Philippines; \\ ${ }^{3}$ Division of Diagnostic Radiology, \\ Department of Radiology, Philippine \\ General Hospital, University of the \\ Philippines Manila, Manila, Philippines; \\ ${ }^{4}$ College of Medicine, University of the \\ Philippines Manila, Manila, Philippines; \\ ${ }^{5}$ Division of Radiation Oncology, \\ Department of Radiology, Philippine \\ General Hospital, University of the \\ Philippines Manila, Manila, Philippines
}

Correspondence: Michael Tee Department of Physiology, College of Medicine, University of the Philippines Manila, Juan Salcedo Hall, 547 Pedro Gil Street, Manila, Ermita 1000, Philippines $\mathrm{Tel} / \mathrm{Fax}+6328526-4262$

Email mltee@up.edu.ph
Context: While urolithiasis is epidemiologically and mechanistically linked to gout, urologic stone disease is not actively investigated in gout patients. Prevalence estimates on the coexistence of urolithiasis in gout have mostly relied on clinical history alone.

Purpose: To estimate the prevalence of urolithiasis among adult Filipinos with primary gout through clinical history and ultrasonography.

Patients and Methods: Patients diagnosed with primary gout were consecutively enrolled from outpatient clinics of the University of the Philippines Manila-Philippine General Hospital. Clinical data including sex; current age; age at diagnosis, duration of and attack frequency of gout; comorbidities such as hypertension, chronic kidney disease, type 2 diabetes mellitus, and dyslipidemia; personal history of urolithiasis; family history of gout; presence of tophus and laboratory samples to assess general kidney function, serum uric acid level, and urine $\mathrm{pH}$ were obtained from each patient who was subsequently subjected to ultrasonographic examination for urolithiasis. Lithiasic and non-lithiasic patients were identified and compared aggregately in terms of the aforementioned features.

Results: We recruited 121 patients, $86.8 \%$ of whom are male, and 37 (30.6\%; 95\% CI=23.1$39.3 \%$ ) were identified to have urolithiasis of which only $12(9.9 \%)$ had history consistent with urolithiasis and $30(24.8 \%)$ were diagnosed solely through ultrasonography. None of the variables of interest were found to be statistically associated $(P>0.05)$ with urologic stone formation. Conclusion: Urolithiasis among adult Filipino patients with primary gout was found to be more prevalent in this study than previous estimates, which were based only on clinical history. We discovered that $25 / 37(67.6 \%)$ of patients with urolithiasis denied history of urologic stone.

Keywords: calculus, kidney, nephrolithiasis, stone, ultrasound, uric acid

\section{Introduction}

By various and latest estimates, both globally ${ }^{1}$ and in the Philippines, ${ }^{2}$ gout is the most common form of chronic inflammatory arthritis in adults. ${ }^{3}$ Accurate reckoning and interpretation of the prevalence and incidence trends of gout are paramount to health resource planning anywhere, considering the relative accessibility and affordability of its first-line management. ${ }^{1}$ Unfortunately, systemic data-gathering issues due to suboptimal ascertainment and reporting suggest that the burden of this disorder has long been underestimated. ${ }^{1,4,5}$ Addressing gout requires comprehensive clinical and public health interventions given that this impairment, which is metabolic at its core, is both precipitated by numerous risk factors and implicated in several cardiovascular and renal conditions. ${ }^{1,-3,-4,-6-11}$ 
Aside from the apparent musculoskeletal and dermatologic manifestations of gout, hyperuricemia has also been implicated in kidney dysfunction. ${ }^{11,12}$ The most frequent comorbidity among patients with hyperuricemia and gout is nephropathy in the form of either urolithiasis or chronic kidney disease (CKD). ${ }^{13}$ Urolithiasis should be taken seriously among these patients because it can be a mechanistic and therapeutically actionable precursor to CKD. ${ }^{11,12}$

Surprisingly, a formal diagnosis of gout in a patient does not automatically compel the physician to actively probe for the urolithiasis, even if both are pathophysiologically and epidemiologically linked. The conditional work-up, the prescription to start urate-lowering therapy, and the case definition used in relevant population-based assessments for urolithiasis among patients with gout are traditionally contingent only on self-reported history consistent with symptomatic urologic stone disease. , $^{3,-8,13,14}$ Bearing in mind that urolithiasis may remain asymptomatic until it obstructs urine flow, not all patients with gout would report a positive history of urolithiasis that would trigger the use of an imaging modality for the said purpose. Incisively demonstrating the problem in this prevailing algorithm were two elegantly straightforward studies, from two decades ago, which reported that at least half of the outpatients with gout with urolithiasis detected through imaging denied history of the latter. ${ }^{14,15}$

There is an absence of recent local Philippine data on the coexistence of these two related conditions. Thus, we sought 1) to determine the prevalence of urolithiasis, through ultrasonography and clinical history, among consecutively recruited public tertiary hospital outpatients with gout, and 2) to describe these patients in terms of selected clinical and laboratory features, both through a cross-sectional study.

\section{Materials and Methods Study Design}

This undertaking was an observational cross-sectional study conducted in accordance with the Declaration of Helsinki, duly approved by the Research Ethics Board (RAD 2016-326-01) of the University of the Philippines Manila.

\section{Patients}

Between January 2016 and July 2016, adult Filipino patients with primary gout were consecutively enrolled from outpatient clinics of the University of the Philippines-Philippine General Hospital of the Philippines, a public tertiary referral and academic hospital in the capital city of Manila. Patients in all levels of healthcare needs are accommodated by the institution irrespective of socioeconomic and referral source. These circumstances allow the facility to provide adequate clinical exposure to medical undergraduates- and postgraduates-intraining.

Patients were classified as gout using the American College of Rheumatology (ACR)/European League Against Rheumatism (EULAR) 2015 criteria. ${ }^{16}$ Those with secondary causes of gout were never requested to participate and thus excluded. Written informed consent was secured from every included patient.

\section{Study Assessments}

Patients who agreed to participate in the study were individually interviewed and examined by one of the investigators prior to ultrasonographic examination. The following information was elicited from each: contact details for future data verification purposes, age at present, approximate age at gout diagnosis, family history of gout, approximate frequency of attacks per year, presence of tophus, history of symptomatic urolithiasis (defined as one of the following: self-reported spontaneous passing of calculus, clinical history consistent to urolithiasis that was verified by a physician or receipt of treatment for urinary tract stones) and history of asymptomatic or incidental urolithiasis through any imaging modality. Subsequently, appropriate laboratory samples were obtained from each patient to measure the following: estimate glomerular filtration rate (eGFR) derived through the 2009 Chronic Kidney Disease Epidemiology Collaboration (CKD-EPI) equation, ${ }^{17}$ serum uric acid level, and urine $\mathrm{pH}$.

Ultrasonography of the kidneys and urinary bladder of each patient was performed using a low-frequency $(2-5$ $\mathrm{MHz}$ ) convex transducer. Calculi were identified as bright echogenic structures, relative to surrounding tissues, with posterior nonechogenic shadow. Evidence of hydronephrosis, as a surrogate marker for obstructive stone formation, was also sought. ${ }^{18}$ The largest dimension of and number of calculus found were recorded, and the location was categorized into calyces, pelvis, and urinary bladder. Other notable findings on ultrasound were also recorded. Videos of the ultrasonographic examination were recorded for subsequent blind retrospective review and verification by an actively-practicing non-investigator consultant who 
is also a certified fellow of the Philippine College of Radiology - Ultrasound Society of the Philippines.

\section{Statistical Sample Size Estimation and Data Analyses}

The sample size needed for the study was estimated using a formula that utilizes the z-statistic for the chosen level of confidence, expected prevalence of the phenomenon of interest (urolithiasis in patients with primary gout) and the allowable margin of error (as half of the width of the desired confidence interval). ${ }^{19,20}$ The computation arrived at a sample size of at least 97 with the z-statistic set at 1.96 (95\% confidence level chosen), prevalence at 0.5 and allowable margin of error at 0.1 . The expected prevalence was set at 0.5 because this is the value that would give the maximum sample size using the estimation formula at a specified z-statistic and margin of error.

The raw data were checked for consistency and completeness prior to statistical analyses using STATA IC 14.2 (StataCorp LLC). The patients and the laboratory were contacted for data verification in the case of irregularities or incompleteness in the dataset. Data with categorical variables were summarized into frequencies and percentages, while those with continuous variables were summarized into arithmetic mean \pm standard deviation (SD). The 95\% confidence interval (CI) for the prevalence estimate of the phenomenon of primary interest was also computed using the Wilson interval method. ${ }^{21}$ Statistical comparisons involving categorical variables were performed using Fisher exact test, ${ }^{22}$ while those concerning continuous variables were done through independent unequalvariance (Welch) $t$-test, ${ }^{23}$ with two-tailed test $P<0.05$ considered statistically significant in both cases.

\section{Results}

A total of 121 patients diagnosed with primary gout, the majority $(86.8 \%)$ of whom are male, were included in the study (Table 1). Three quarters of the patients were between $40-70$ years old. There was a markedly high variability in the recorded duration and acute flare frequency of the disease among the patients, centering at the mean of 6.8 years and 4.23 attacks per year, respectively. Noted significant comorbidities afflicting the patients include hypertension (47.1\%), chronic kidney disease or CKD (44.6\%), dyslipidemia (22.3\%), and type 2 diabetes mellitus or T2DM (15.7\%). Twelve (9.9\%) patients had clinical history consistent with symptomatic urologic stone disease, while none reported a previous incidental finding of calculus on imaging.

The prevalence of urolithiasis detected using ultrasonography in our cross-sectional analysis was $24.8 \%$ (95\% $\mathrm{CI}=17.4-33.5 \%$ ). Evidence of urolithiasis was found in this manner in five out of 12 patients with previous clinical history for kidney stone disease as well as in 25 other patients lacking the said characteristic (Table 2). Combining the number of patients with positive clinical history and those with positive ultrasonographic findings yielded a prevalence of $30.6 \%$ (95\% CI $=23.1-39.3 \%)$. There was no statistically significant difference $(P=0.08)$ between the duration of the disease, in mean \pm standard deviation (SD) years, between patients with both relevant consistent clinical history and ultrasonographic evidence of stone disease (11.6 \pm 8.9 years) and patients who were diagnosed to be urolithiasic solely through the imaging modality of interest ( $8.1 \pm 5.3$ years).

Two-thirds of the calculi found through ultrasound were observed in the calyces. The rest were found in the pelvis $(23.3 \%)$ or urinary bladder $(10.0 \%)$. The majority of the stones were subcentimeter in size $(76.7 \%)$ and were nonobstructing (90.0\%). Multiple stones were found in half of these patients (Table 3). Other ultrasound findings among gout patients included renal cysts, which were seen in as much as $36 \%$ of the sample. Renal parenchymal disease or sonographic evidence of chronic kidney disease was appreciated in $11 \%$ of patients with renal calculi, and $15 \%$ among those without calculi. Infrequent incidental findings were fatty liver changes, urinary bladder diverticulum, intraluminal sediments, and solid renal and urinary bladder masses.

Comparing the clinically or ultrasonographicallylithiasic $(n=37)$ and non-lithiasic $(n=84)$ groups of patients through univariate analyses of selected categorical variables revealed no statistically significant association with urolithiasis. No statistically significant difference in numerical variables such as current age, age at gout diagnosis, duration of gout, serum uric acid level, and eGFR was found as well (Table 1).

\section{Discussion}

\section{Prevalence of Urolithiasis Among Patients with Gout}

Patients with hyperuricemia or gout have an elevated risk of urolithiasis due to the twin conditions of having serum urate level greater than $0.42 \mathrm{mmol} / \mathrm{L}$ and acidic urine. ${ }^{3,12,24}$ These patients have persistently acidic urine due to a defect in the renal production of ammonia, 
Table I Characteristics of the Patients Included in the Study

\begin{tabular}{|c|c|c|c|c|}
\hline Characteristic & Total & With Urolithiasis & Without Urolithiasis & $\boldsymbol{P}$ \\
\hline Patient number, n (\%) & $121(100)$ & $37(30.6)$ & $84(69.4)$ & \\
\hline \multicolumn{5}{|l|}{ Sex, n (\%) } \\
\hline Female & $16(13.2)$ & $6(37.5)$ & $10(62.5)$ & 0.57 \\
\hline Male & $105(86.8)$ & $31(29.5)$ & $74(70.5)$ & \\
\hline Age, in years $($ mean $\pm S D)$ & $59.0 \pm 13.3$ & $62.1 \pm 13.0$ & $57.5 \pm 13.4$ & 0.08 \\
\hline $\begin{array}{l}\text { Age at gout diagnosis, in years } \\
(\text { mean } \pm S D)\end{array}$ & $52.3 \pm 14.8$ & $54.0 \pm 15.6$ & $51.6 \pm 14.5$ & 0.43 \\
\hline $\begin{array}{l}\text { Duration of gout, in years } \\
\text { (mean } \pm S D)\end{array}$ & $6.8 \pm 7.8$ & $7.3 \pm 7.3$ & $6.6 \pm 8.1$ & 0.64 \\
\hline $\begin{array}{l}\text { Frequency of attacks, per year } \\
(\text { mean } \pm S D)\end{array}$ & $4.3 \pm 5.1$ & $8.1 \pm 2.6$ & $8.6 \pm 2.5$ & 0.33 \\
\hline \multicolumn{5}{|l|}{ With comorbidity, n (\%) } \\
\hline Hypertension & $57(47.1)$ & $19(33.3)$ & $38(66.7)$ & 0.56 \\
\hline CKD & $54(44.6)$ & $20(37.0)$ & $34(63.0)$ & 0.23 \\
\hline Dyslipidemia & $27(22.3)$ & $10(37.0)$ & $17(63.0)$ & 0.48 \\
\hline T2DM & $19(15.7)$ & $7(36.8)$ & $12(63.2)$ & 0.59 \\
\hline With family history of gout, $n(\%)$ & $38(31.4)$ & $10(26.3)$ & $28(73.7)$ & 0.53 \\
\hline With tophus, n (\%) & $48(39.7)$ & $15(31.3)$ & $33(68.8)$ & 1.00 \\
\hline $\begin{array}{l}\text { Serum uric acid, in } \mu \mathrm{mol} / \mathrm{L} \\
(\mathrm{mean} \pm \mathrm{SD})\end{array}$ & $499.7 \pm 154.7$ & $481.8 \pm 154.7$ & $511.6 \pm 148.7$ & 0.33 \\
\hline eGFR, in $\mathrm{mL} / \mathrm{min} / \mathrm{l} .73 \mathrm{~m}^{2}$ & $62.5 \pm 26.7$ & $64.2 \pm 26.8$ & $61.7 \pm 26.8$ & 0.64 \\
\hline Urine $\mathrm{pH}$ & $5.6 \pm 0.6$ & $5.4 \pm 1.2$ & $5.7 \pm 1.9$ & 0.30 \\
\hline
\end{tabular}

Abbreviations: CKD, chronic kidney disease; eGFR, estimated glomerular filtration rate; SD, standard deviation; T2DM, type 2 diabetes mellitus.

Table 2 Categorization of Study Patients in Terms of HistoryBased and Ultrasonographic Detection of Urolithiasis

\begin{tabular}{|l|l|l|l|l|}
\hline \multirow{2}{*}{} & & \multicolumn{2}{|l|}{$\begin{array}{l}\text { History of } \\
\text { Urolithiasis }\end{array}$} & \multirow{2}{*}{ Total } \\
\cline { 3 - 4 } & & With & Without & \\
\cline { 3 - 4 } & & 5 & 25 & 30 \\
& Ultrasonography & With urolithiasis & 54 & 91 \\
\cline { 3 - 4 } & Without urolithiasis & 7 & 84 & 121 \\
\hline Total & 12 & 109 & \\
\hline
\end{tabular}

creating an environment favorable to precipitate uric acid which can subsequently lead to calcium oxalate crystallization. ${ }^{12}$ With the rise in prevalence and incidence of gout, especially in association with those of metabolic syndrome and its individual components, ${ }^{25,26}$ the burden of urolithiasis in these patients is expected to increase as well.

The coexistence of hyperuricemia or gout and urolithiasis must be actively probed whenever a patient is diagnosed with either one, as management options are correspondingly altered when co-occurrence is demonstrated. For instance, uricosuric agents for gout are
Table 3 Ultrasonographic Characteristics of Detected Calculi in Gout Patients with Urolithiasis.

\begin{tabular}{|c|c|}
\hline Characteristic & $\begin{array}{l}\text { Summary Measure, } n(\%) \\
(n=30)\end{array}$ \\
\hline \multicolumn{2}{|l|}{ Location of calculus } \\
\hline Calyces & $20(66.7)$ \\
\hline Pelvis & $7(23.3)$ \\
\hline Urinary bladder & $3(10.0)$ \\
\hline \multicolumn{2}{|l|}{ Largest dimension of calculus } \\
\hline$<1 \mathrm{~cm}$ & $23(76.7)$ \\
\hline $\mathrm{I}-2 \mathrm{~cm}$ & $5(16.7)$ \\
\hline$>2 \mathrm{~cm}$ & $2(7.7)$ \\
\hline Multiple stone formation & $15(50.0)$ \\
\hline Obstructive stone formation & $3(10.0)$ \\
\hline
\end{tabular}

contraindicated when the patient is urolithiasic., ${ }^{1,3,24}$ However, the latest versions of clinical practice guidelines on gout, both locally ${ }^{27}$ and internationally, ${ }^{28-31}$ do not directly address this issue beyond stating contraindications to certain medications when both diseases are established in the patient by clinical history. To our knowledge, only 
the 2012 ACR guidelines ${ }^{32}$ specifically mention the use of imaging (ultrasonography in particular) as a comorbidity workup among patients with gout only when corroborated by previous history of urolithiasis.

Roughly half a century before, the prevalence of urolithiasis among Filipino patients with gout was estimated at $17.3 \%(95 \% \mathrm{CI}=13.2-22.4 \%){ }^{33}$ statistically overlapping with the figure $(14 \% ; 95 \% \mathrm{CI}=12-17 \%)$ from a recent meta-analysis of epidemiologic studies tackling the coexistence of both diseases. ${ }^{8}$ However, this dated local clinical study, involving patients accrued from a private tertiary hospital and an undisclosed private clinic, like most other population-based studies relied solely on self-reported history consistent with urolithiasis among patients with gout in determining the prevalence estimate. More recent findings suggest that at least half of patients with gout assessed to have urolithiasis by imaging are asymptomatic for urologic stone disease. ${ }^{14,15}$ This investigation is thus the first to assess whether the use of ultrasonography, a low-cost, low-risk, and non-invasive imaging tool, adds value to clinical history in diagnosing urolithiasis among Filipino patients with gout seen at a public tertiary hospital in the Philippine capital.

Apart from the change in management of gout in the presence of urolithiasis in the same patient, urolithiasis potentiated by hyperuricemia must be investigated because it is a risk factor with a mechanistically plausible basis for CKD. ${ }^{11,-12,-34-36}$ Alarmingly, the risk contributed by urolithiasis is elevated from baseline independent of symptomatology (or the lack thereof). ${ }^{37}$ Supporting this finding is a study of kidneys from transplant donors with asymptomatic stones which revealed a significantly increased likelihood of radiographic findings such as renal parenchymal atrophy and focal renal scarring compared to transplant donors with neither clinically- nor radiographicallyapparent stones. ${ }^{38}$ Thus, the body of evidence prior to this work points to the insufficiency of clinical history of urolithiasis alone to guide concomitant therapy in delaying the progression of chronic renal insufficiency among at least some of the patients of interest.

In our group of outpatients with gout consecutively recruited from our center, the preponderance of males (86.8\%; 95\% CI=79.6-91.7\%), hypertensives (47.1\%; $95 \% \quad \mathrm{CI}=38.4-60.0 \%)$, and diabetics $(15.7 \%$; 95\% $\mathrm{CI}=10.3-23.2 \%)$ is statistically consistent with those found in other local studies performed previously. ${ }^{39,40}$ Our cohort also had statistically lower prevalence of hypertension $(47.1 \%$; 95\% $\mathrm{CI}=38.4-56.0 \%$ vs $69.0 \%$;
95\% CI $=67.2-70.7 \%), \quad$ T2DM $\quad(15.7 \% ; 95 \% \quad \mathrm{CI}=10.3-$ $23.2 \%$ vs $25.0 \% ; 95 \% \mathrm{CI}=23.4-26.7 \%$ ). and dyslipidemia (22.3\%; 95\% CI $=15.8-30.5 \%$ vs $60.2 \%$; 95\% CI $=58.4-$ $62.0 \%$ ) than the latest corresponding cohort figures from the US. However, the prevalence of CKD in our cohort is statistically higher $(44.6 \% ; 95 \% \quad \mathrm{CI}=36.1-53.5 \% \quad$ vs $28.0 \%$; 95\% CI=26.7-30.1\%). ${ }^{26}$ The proportion of patients who have clinical history of urolithiasis in this study (9.9\%; 95\% CI $=5.8-16.5 \%)$ had no statistically significant difference from the locally estimated proportion 45 years ago $(17.3 \%$; $95 \% \mathrm{CI}=13.2-22.4 \%){ }^{33}$

Ultrasonography demonstrated that $30(24.8 \%$; $95 \%$ $\mathrm{CI}=17.4-33.5 \%$ ) out of 121 patients in our study had visualizable urologic stones at the time of examination. This estimate is statistically larger by approximately 1.5-times than the previously published estimate for Filipinos. ${ }^{33}$ The majority of these patients in the current study (25) denied history consistent with symptomatic urologic stone disease, while imaging evidence of stones was not found in seven out of 12 patients who reported such history. These trends involving ultrasonography and clinical history are consistent from those reported in a recently published study from Brazil with highly similar objectives, design, and patient population of interest. ${ }^{41}$ One possible explanation for the apparent discrepancy between history and ultrasound findings is that during the moment of study participation, the patients of interest were in the course of the disease between passage of existing and formation of new clinically- and ultrasonographicallyapparent calculi.

Ultimately, the diagnosis of urolithiasis through ultrasound increased the detection rate by $60 \%$ more than that by clinical history alone. When both modalities are jointly considered, the detection rate further rose to $67.6 \%$ (reaching a prevalence estimate of $30.6 \%$; 95\% CI=23.1-39.3\%) more than when clinical history was the sole basis for determining urolithiasis in this cohort. This rise in detection is larger than the $\sim 50 \%$ increase reported in the landmark 2005 study that first argued for the use of imaging modalities on top of clinical history to diagnose urolithiasis in patients with gout. ${ }^{14}$

\section{Ultrasonography to Detect Urolithiasis Among Patients with Gout}

Several issues surrounding the sole use of ultrasonography for imaging in this study deserve recognition. This modality is known to be highly operator-dependent, ${ }^{42}$ making precise assessment of its clinical accuracy through 
synthesis of evidence from various centers and periods theoretically challenging. Stones less than $5 \mathrm{~mm}$ are increasingly difficult to visualize, if seen at all, ${ }^{19,43}$ and there are several vascular and nonvascular sonographic mimics that can be mistaken for a stone. ${ }^{44}$ Furthermore, increase in patient abdominal body mass, relative calculi size, and certain locations of stone lodgment have been demonstrated to contribute to the risk of false-negative findings on ultrasound. ${ }^{45}$ Studies that compare this modality head-on with the recognized gold standard for imaging urolithiasis, computed tomography (CT), give a pooled estimate of its sensitivity and specificity at only $70.2 \%(95 \% \mathrm{CI}=67.1-73.2 \%)$ and $75.4 \%(95 \% \mathrm{CI}=72.5-$ $78.2 \%)$ respectively, which are improved by certain clinical and anatomic factors. ${ }^{46}$

On the other hand, the first-line choice for imaging, particularly given the specific clinical context covered by the present study, is still contentious. The cost of CT-based imaging remains to be prohibitive for routine screening purposes, especially in the setting of an unevenlydistributed middle-income country such as the Philippines, and the risks bestowed by ionizing radiation exposure cannot be overemphasized. ${ }^{19,43,47}$ This issue is reflected in the differences in the urolithiasis imaging guidelines of leading medical specialty bodies such as the American College of Radiology (ACR), American Urological Association (AUA), and the European Association of Urology (EAU). ${ }^{19}$ In general, while ACR and AUA explicitly recommend $\mathrm{CT}$ as the primary imaging modality for urolithiasis in most cases, ${ }^{48,49}$ EAU prescribes its use only after inconclusive findings on ultrasound. ${ }^{50}$ Both American societies, together with the American Academy of Emergency Medicine (AAEM), also prefer ultrasonography (together with or over CT) in the management and monitoring of recurrent or known urolithiasic patients. ${ }^{48,49,51}$ The large breakthrough STONE trial also notably showed that the presumed difference in diagnostic accuracy between ultrasonography (either by an emergency physician or a radiologist) and CT did not translate to appreciable difference in terms of relevant outcomes such as the incidence of high-risk diagnoses with complications, adverse events, pain score, return emergency department visits, hospitalizations, and even intra-study diagnostic accuracy. ${ }^{52}$ It is important to note that the aforementioned studies, arguably, address the clinical context of interest only indirectly, since they involved patients with symptomatic urologic stone disease usually in an emergent setting (whereas we specifically sought to detect asymptomatic or incidental urologic stones in gout patients). All previous investigations that directly identified urolithiasis through imaging in patients with gout have not directly compared ultrasonography and CT since they only used either one or the other. ${ }^{14,-15,-41,-}$ ${ }^{53-56}$ Finally, the increase in urolithiasis detection rate with CT compared to clinical history alone in these studies is either comparable to or smaller than the increase found in our present ultrasonographic study (although the differences in true prevalence of the phenomenon of interest in the sites where the studies were performed may have been a confounder). ${ }^{15,-53-56}$

\section{Possible Implications of Findings in Managing Gout Patients with Urolithiasis}

We did not find any significant associations with an a priori-generated list of clinical, laboratory, and ultrasonographic variables that may be useful in our setting to predict urolithiasis in patients with gout. On one hand, our study may be underpowered to identify such pertinent factors, should they exist, since the eventual size differences of the lithiasic and non-lithiasic subgroups may have precluded statistically significant findings by virtue of imbalanced contingency tables and wide confidence intervals. On the other, these findings may suggest that clinicians should be directed to actively screen for urolithiasis in all patients with gout through a combination of clinical history and ultrasonography at the very least, since no significant factor directly or inversely predictive of urolithiasis has been found.

There is considerable evidence that asymptomatic and/or radiographically incidental urologic stone formation is associated with worse long-term outcomes compared to absolutely non-stone-formers. However, one issue arising from increased identification of this entity through imaging is the risk-benefit ratio acceptability of available therapeutic modalities, other than active surveillance ${ }^{57,58}$ and selection between uricosuric agents versus xanthine oxidase inhibitors, that may be recommended in this context. While the recommended pharmacologic dissolution and expulsive therapy seem reasonably safe, ${ }^{50}$ the evidence base involving treatment of this population of interest is yet to be made comprehensive and definitive. Moreover, urosurgical treatment modalities in this context have been demonstrated to be both ineffective $e^{57,59}$ and outright detrimental in the long run. ${ }^{60}$ 


\section{Limitations of the Study}

An epidemiologic limitation of this study is brought about by its single-centric tertiary care focus. The estimates generated from this work, as with those from other studies which are mostly of the same study circumstances, are less likely to be representative of the true values since most patients with gout are managed exclusively in the primary care or community-based setting. ${ }^{1,8}$ Differences in healthseeking behavior and in the choice of medical care facility level may probably be due to significant differences in clinical and pathophysiological characteristics. In terms of the ultrasonographic technique utilized in this study, we were not able to use the "twinkling sign"-based color Doppler ultrasound mode which has been documented to improve the accuracy of detecting calculi compared to the standard grayscale mode. ${ }^{61,62}$ While all patients in the study were prescribed with urate-lowering agents beforehand, we did not attempt to involve this clinical characteristic in the analyses because compliance as confounding could neither be ascertained or assumed - reporting spurious findings is thus highly probable in doing so. Finally, the number of variables we interrogated for possible association with urologic stone formation was relatively few compared to similar studies that tackle the same clinical context. It can be argued on our part, however, that increasing the number of variables to be analyzed post hoc runs the risk of data-dredging for correlates with little to no predictive power or clinical utility.

\section{Conclusion}

The results of this study suggest that the prevalence of urolithiasis coexisting with primary gout, at least among adult Filipino outpatients in the tertiary care setting, is considerably higher than that accounted for by clinical history alone. In doing so, the present investigation provided an update to the 45-year old prior and smaller prevalence estimate of this phenomenon in Filipinos. We have demonstrated that the use of standard ultrasound significantly improved the rate of detecting asymptomatic urolithiasis in this clinical context, consistent with previous reports. Given these and their corresponding implications in the management of the component diseases involved, active screening for urologic stone disease using both clinical history and ultrasonography, as an initial imaging modality that is non-invasive, safe, and cost-efficient, should strongly be considered in patients with gout.
Future studies should hopefully deal with several issues highlighted by this work. We recommend the conduct of a local, larger, multi-centric, multi-care level and/ or community-based study in order to arrive at a more representative prevalence and/or incidence estimates of the phenomenon of interest. An investigation of such magnitude will permit credible probing for relevant associations of numerous clinical, laboratory, and ultrasonographic variables with urolithiasis in Filipino patients with gout, thus better informing relevant clinical guidelines and public health policies. Head-on diagnostic accuracy comparisons between ultrasonographic and CTbased modalities in this patient population should also be undertaken, as well as assessing whether stones not found on ultrasound but detectable on CT are clinically consequential in both the short- and long-term. Finally, the search for and/or optimization of specific treatments for asymptomatic urolithiasis in primary gout should also be performed.

\section{Acknowledgments}

For their invaluable contributions to this study, the authors are deeply grateful to Dr. Rogelio I. de Jesus (consultant radiologist) and Dr. Julian A. Santos (resident radiologist) from the Department of Radiology, Philippine General Hospital, University of the Philippines Manila.

\section{Disclosure}

The authors declare no conflicts of interest for this work.

\section{References}

1. Dehlin M, Jacobsson L, Roddy E. Global epidemiology of gout: prevalence, incidence, treatment patterns and risk factors. Nat Rev Rheumatol. 2020;16:380-390. doi:10.1038/s41584-020-0441-1

2. Dans LF, Salido EO, Penserga EG, Navarra SV. National Nutrition and Health Survey (NNHeS): prevalence of rheumatic diseases among adult Filipinos. Phil J Int Med. 2006;44:297-303.

3. Dalbeth N, Choi HK, Joosten LAB, et al. Gout. Nat Rev Dis Primers. 2019;5:69. doi:10.1038/s41572-019-0115-y

4. Trifiro G, Morabito P, Cavagna L, et al. Epidemiology of gout and hyperuricaemia in Italy during the years 2005-2009: a nationwide population-based study. Ann Rheum Dis. 2013;72:694-700. doi:10.1136/annrheumdis-2011-201254

5. Prasad P, Krishnan E. Filipino gout: a review. Arthritis Care Res (Hoboken). 2014;66(3):337-343. doi:10.1002/acr.22118

6. Kramer HM, Curhan G. The association between gout and nephrolithiasis: the National Health and Nutrition Examination Survey III, 1988-1994. Am J Kidney Dis. 2002;40(1):37-42. doi:10.1053/ ajkd.2002.33911

7. Kramer HJ, Choi HK, Atkinson K, Stampfer M, Curhan GC. The association between gout and nephrolithiasis in men: the Health Professionals' Follow-Up Study. Kidney Int. 2003;64:1022-1026. doi:10.1046/j.1523-1755.2003.t01-2-00171.x 
8. Roughley MJ, Belcher J, Mallen CD, Roddy E. Gout and risk of chronic kidney disease and nephrolithiasis: meta-analysis of observational studies. Arthritis Res Ther. 2015;17:90. doi:10.1186/s13075015-0610-9

9. Li X, Meng X, Timofeeva M, et al. Serum uric acid levels and multiple health outcomes: umbrella review of evidence from observational studies, randomised controlled trials, and Mendelian randomisation studies. BMJ. 2017;357:j2376. doi:10.1136/bmj.j2376

10. Stack AG, Johnson ME, Blak B, et al. Gout and the risk of advanced chronic kidney disease in the UK health system: a national cohort study. BMJ Open. 2019;9:e031550. doi:10.1136/bmjopen-2019-031550

11. Mount DB. The kidney in hyperuricemia and gout. CurrOpin Nephrol Hypertens. 2013;22:216-223. doi:10.1097/MNH.0b013e32835ddad2

12. Wiederkehr MR, Moe OW. Uric acid nephrolithiasis: a systemic metabolic disorder. Clin Rev Bone Miner Metab. 2011;9:207-217. doi:10.1007/s12018-011-9106-6

13. Zhu Y, Pandya BJ, Choi HK. Comorbidities of gout and hyperuricemia in the US general population: NHANES 2007-2008. Am J Med. 2012;125:679-687. doi:10.1016/j.amjmed.2011.09.033

14. Alvarez-Nemegyei J, Medina-Escobedo M, Villanueva-Jorge S, Vasquez-Mellado J. Prevalence and risk factors for urolithiasis in primary gout: is a reappraisal needed? J Rheumatol. 2005;32:2189-2191.

15. Shimizu T, Hori H. The prevalence of nephrolithiasis in patients with primary gout: a cross-sectional study using helical computed tomography. J Rheumatol. 2009;36:1958-1962. doi:10.3899/jrheum.081128

16. Neogi T, Jansen TLT, Dalbeth N, et al. Gout classification criteria: an American College of Rheumatology/European League Against Rheumatism collaborative initiative. Ann Rheum Dis. 2015;2015 (74):1789-1798. doi:10.1136/annrheumdis-2015-208237

17. Levey AS, Stevens LA, Schmid $\mathrm{CH}$, et al. A new equation to estimate glomerular filtration rate. Ann Intern Med. 2009;150 (9):604-612. doi:10.7326/0003-4819-150-9-200905050-00006

18. Fosgate GT. Practical sample size calculations for surveillance and diagnostic investigations. J Vet Diagn Invest. 2009;21:3-14. doi:10.1177/104063870902100102

19. Brisbane W, Bailey MR, Sorensen MD. An overview of kidney stone imaging techniques. Nat Rev Urol. 2016;13:654-662. doi:10.1038/ nrurol.2016.154

20. Arya R, Antonisamy B, Kumar S. Sample size estimation in prevalence studies. Indian J Pediatr. 2012;79(11):1482-1488. doi:10.1007/ s12098-012-0763-3

21. Brown LD, Cat TT, DasGupta A. Interval estimation for a proportion. Stat Sci. 2001;16:101-133. doi:10.1214/ss/1009213286

22. Kim HY. Statistical notes for clinical researchers: chi-squared test and Fisher's exact test. Restor Dent Endod. 2017;42(2):152-155. doi:10.5395/rde.2017.42.2.152

23. Delacre M, Lakens D, Leys C. Why psychologists should by default use Welch's t-test method instead of Student's t-test. Int Rev Soc Psychol. 2017;30(1):92-101. doi:10.5334/irsp.82

24. Terkeltaub R. Update on gout: new therapeutic strategies and options. Nat Rev Rheumatol. 2010;6:30-38. doi:10.1038/nrrheum.2009.236

25. Thottam GE, Krasnokutsky S, Pillinger MH. Gout and metabolic syndrome: a tangled web. Curr Rheumatol Rep. 2017;19:60. doi:10.1007/s11926-017-0688-y

26. Elfishawi MM, Zleik N, Kvrgic Z, et al. The rising incidence of gout and the increasing burden of comorbidities: a population-based study over 20 years. J Rheumatol. 2018;45(4):574-579. doi:10.3899/ jrheum. 170806

27. Li-Yu J, Salido EO, Manahan SE, et al. Philippine Clinical Practice Guidelines for the Management of Gout 2008. Philippine Rheumatol Assoc. 2008.

28. Sivera F, Andres M, Carmona L, et al. Multinational evidence-based recommendations for the diagnosis and management of gout: integrating systematic literature review and expert opinion of a broad panel of rheumatologists in the 3e initiative. Ann Rheum Dis. 2014;73:328-335. doi:10.1136/annrheumdis-2013-203325
29. Richette P, Doherty M, Pascual E, et al. Updated EULAR evidence-based recommendations for the management of gout. Ann Rheum Dis. 2017;76(1):29-42. doi:10.1136/annrheumdis-2016-209707

30. Yu KH, Chen DY, Chen JH, Chen SY, Chen SM, Cheng TT. Management of gout and hyperuricemia: multidisciplinary consensus in Taiwan. Int J Rheumatol Dis. 2018;21(4):772-787. doi:10.1111/ 1756-185X.13266

31. FitzGerald JD, Dalbeth N, Mikuls T, et al. 2020 American College of Rheumatology Guideline for the Management of Gout. Arthritis Care Res (Hoboken). 2020;72(6):744-760. doi:10.1002/acr.24180

32. Khanna D, FitzGerald JD, Khanna P, et al. 2012 American College of Rheumatology guidelines for management of Gout. Part 1: systematic nonpharmacologic and pharmacologic therapeutic approaches to hyperuricemia. Arthritis Care Res (Hoboken). 2012;64(10):14 31-1446. doi:10.1002/acr.21772

33. Torralba TP, Bayani-Sioson PS. The Filipino and gout. Semin Arthritis Rheum. 1975;4(4):307-320. doi:10.1016/0049-0172(75)90015-3

34. Rule AD, Krambeck AE, Lieske JC. Chronic kidney disease in kidney stone formers. Clin J Am Soc Nephrol. 2011;6:2069-2075. doi: $10.2215 /$ CJN. 10651110

35. Keddis MT, Rule AD. Nephrolithiasis and loss of kidney function. CurrOpin Nephrol Hypertens. 2013;22:390-396. doi:10.1097/ MNH.0b013e32836214b9

36. Zisman AL, Evan AP, Coe FL, Worcester EM. Do kidney stone formers have a kidney disease? Kidney Int. 2015;88:1240-1249. doi:10.1038/ki.2015.254

37. Dhondup T, Kittanamongkolchai W, Vaughan LE, et al. Risk of ESRD and mortality in kidney and bladder stone formers. $\mathrm{Am}$ J Kidney Dis. 2018;72(6):790-797. doi:10.1053/j.ajkd.2018.06.012

38. Lorenz EC, Lieske JC, Vrtiska TJ, et al. Clinical characteristics of potential kidney donors with asymptomatic kidney stones. Nephrol Dial Transplant. 2011;26:2695-2700. doi:10.1093/ndt/gfq769

39. Hernandez ATS, Tee KD, Penserga E, Salido EO. Renal function of patients with gout on initial visit at a rheumatology clinic. Phil $J$ Int Med. 2016;54(1):1-6.

40. Hernandez AT, Tee K, Salido E. Clinical profile of Filipino patients with gout seen in adult rheumatology clinics in the National Capital Region, Philippines. Phil J Int Med. 2016;54(3):1-4.

41. Hoff LS, Goldenstein-Schainberg C, Fuller R. Nephrolithiasis in gout: prevalence and characteristics of Brazilian patients. $A d v$ Rheumatol. 2020;60(1):2. doi:10.1186/s42358-019-0106-4

42. Stasi G, Ruoti EM. A critical evaluation in the delivery of the ultrasound practice: the point of view of the radiologist. Ital J Med. 2015;9(1):5. doi:10.4081/itjm.2015.502

43. Alabousi A, Patlas MN, Mellnick VM, Chernyak V, Farshait N, Katz DS. Renal colic imaging: myths, recent trends, and controversies. Can Assoc Radiol J. 2019;70(2):164-171. doi:10.1016/j.carj.2018.09.008

44. Durr-e-Sabih KAN, Craig M, Worrall JA. Sonographic mimics of renal calculi. J Ultrasound Med. 2004;23(10):1361-1367. doi:10.78 63/jum.2004.23.10.1361

45. Nery DR, Costa YB, Mussi TC, Baroni RH. Epidemiological and imaging features that can affect the detection of ureterolithiasis on ultrasound. Radiol Bras. 2018;51(5):287-292. doi:10.1590/01003984.2017.0113

46. Wong C, Teitge B, Ross M, Young P, Robertson HL, Lang E. The accuracy and prognostic value of point-of-care ultrasound for nephrolithiasis in the emergency department: a systematic review and meta-analysis. AcadEmerg Med. 2018;25(6):684-698.

47. McCarthy CJ, Baliyan V, Kordbacheh H, Sajjad Z, Sahani D, Kambadakone A. Radiology of renal stone disease. Int J Surg. 2016;36:638-646. doi:10.1016/j.ijsu.2016.10.045

48. Moreno CC, Beland MD, Goldfarb S, et al. American College of Radiology (ACR) Appropriateness Criteria ${ }^{\circledR}$ : acute onset flank pain suspicion of stone disease (Urolithiasis). 2015. Available from: https://acsearch.acr.org/docs/69362/Narrative. Accessed June 30, 2020. 
49. Fulgham PF, Assimos DG, Pearle MS, Preminger GM Clinical effectiveness protocols for imaging in the management of ureteral calculous disease: american Urological Association (AUA) Technology Assessment. 2012. Available from: https://www.auanet.org/guidelines/ imaging-for-ureteral-calculous-disease. Accessed June 30, 2020.

50. Turk C, Neisius A, Petrik A et al. European Association of Urology (EAU) Guidelines on Urolithiasis. 2017. Available from: https://uro web.org/wp-content/uploads/EAU-Guidelines-onUrolithiasis 2017 10-05V2.pdf. Accessed June 30, 2020.

51. Mills L, Morley EJ, Soucy Z, Vilke GM, Lam SHF. Ultrasound for the diagnosis and management of suspected urolithiasis in the emergency department. J Emerg Med. 2018;54(2):215-220. doi:10.1016/j. jemermed.2017.09.020

52. Smith-Bindman R, Aubin C, Bailitz J, et al. Ultrasonography versus computed tomography for suspected nephrolithiasis. $N$ Engl J Med. 2014;371(12):1100-1110. doi:10.1056/NEJMoa1404446

53. Shimizu T, Kitada H, Umeyama M, Hori H, Takasaki N. Novel evaluation of nephrolithiasis as a complication of gout: a cross-sectional study using helical computerized tomography. J Urol. 2013;189:1747-1752. doi:10.1016/j.juro.2012.11.076

54. Ramos FP, Barbosa AT, Souza RB, Seragioli F, Giorgi RDN, Rosa RF. Nephrolithiasis as a complication of gout: a cross-sectional study with helical computed tomography. Ann Rheum Dis. 2018;77 (Supp12):142.1-142. doi:10.1136/annrheumdis-2018-eular.1555

55. Shimizu T, Hori H, Umeyama M, Shimizu K. Characteristics of gout patients according to the laterality of nephrolithiasis: A cross-sectional study using helical computed tomography. Int J Rheum Dis. 2019;22(4):567-573. doi:10.1111/1756-185X.13443
56. Li ZX, Jiao GL, Zhou SM, Cheng ZY, Bashir S, Zhou Y. Evaluation of the chemical composition of nephrolithiasis using dual-energy CT in Southern Chinese gout patients. BMC Nephrol. 2019;20:273. doi:10.1186/s12882-019-1441-8

57. Goldsmith ZG, Lipkin ME. When (and how) to surgically treat asymptomatic renal stones. Nat Rev Urol. 2012;9:315-320. doi:10.1038/nrurol.2012.43

58. Dropkin BM, Moses RA, Sharma D, Pais VM Jr. The natural history of nonobstructing asymptomatic renal stones managed with active surveillance. J Urol. 2015;193(4):1265-1269. doi:10.1016/j.juro.20 14.11.056

59. Ludwig WW, Ziemba JB, Matlaga BR. Difference of opinion asymptomatic lower pole stone $<1 \mathrm{~cm}$ : to treat or not to treat? Opinion: do not treat. Int Braz J Urol. 2016;42(2):185-187. doi:10.1590/S1677-5538.IBJU.2016.02.04

60. Lin SY, Lin CL, Chang CH, et al. Comparative risk of chronic kidney diseases in patients with urolithiasis and urological interventions: a longitudinal population-based study. Urolithiasis. 2017;45:4 65-472. doi:10.1007/s00240-016-0929-y

61. Mitterberger M, Aigner F, Pallwein L, et al. Sonographic detection of renal and ureteral stones. Value of the twinkling sign. Int Braz J Urol. 2009;35(5):532-539. doi:10.1590/S1677-55382009000500004

62. Yavuz A, Ceken K, Alimoglu E, Kabaalioglu A. The reliability of color doppler "twinkling" artifact for diagnosing millimetrical nephrolithiasis: comparison with B-Mode US and CT scanning results. J Med Ultrason. 2015;42:215-222. doi:10.1007/s10396-0140599-8
Research and Reports in Urology

\section{Publish your work in this journal}

Research and Reports in Urology is an international, peer-reviewed, open access journal publishing original research, reports, editorials, reviews and commentaries on all aspects of adult and pediatric urology in the clinic and laboratory including the following topics Pathology, pathophysiology of urological disease; Investigation and
Dovepress

treatment of urological disease; Pharmacology of drugs used for the treatment of urological disease. The manuscript management system is completely online and includes a very quick and fair peer-review system, which is all easy to use. Visit http://www.dovepress.com/ testimonials.php to read real quotes from published authors. 